\title{
Assessment of education effects on patient involvement and bariatric treatment outcome: an observational study
}

\author{
Regina Sierżantowicz', Jerzy R. Ładny ${ }^{2}$, Jolanta Lewko ${ }^{3}$, Hady Razak Hady² \\ ${ }^{1}$ Department of Surgical Nursing, Medical University of Bialystok, Bialystok, Poland \\ ${ }^{2}$ Department of General and Endocrine Surgery, Medical University of Bialystok, Bialystok, Poland \\ ${ }^{3}$ Department of Integrated Medical Care, Medical University of Bialystok, Bialystok, Poland
}

Videosurgery Miniinv 2020; 15 (1): 157-165

DOI: https://doi.org/10.5114/wiitm.2019.88649

\begin{abstract}
Introduction: As a result of the growing number of people with obesity, the popularity of bariatric surgery has been systematically increasing. It has not yet been explored whether individual education of the patient can contribute to long-term success in weight reduction after bariatric treatment.

Aim: To implement and compare the effects of different education methods, versus receiving one-time written information in the form of a guidebook, on patient involvement in abiding by lifestyle recommendations after laparoscopic sleeve gastrectomy (LSG) bariatric treatment.

Material and methods: The study included 160 patients with morbid obesity. The education session study participants were 100 patients after sleeve gastrectomy, with whom three education sessions were planned, and who were enrolled in the study. The control group consisted of 60 patients who underwent sleeve gastrectomy, and before discharge from the department, they received one-time written recommendations in the form of a guidebook.

Results: We confirmed that the three education sessions we conducted with the study group after LSG had a significant impact on weight loss. The control group, which received only written information, achieved weight loss and abided by the written recommendations, although to a lesser extent than the study group. The differences were evident particularly in motivation to adhere to recommendations and check-ups, which was significantly lower $(p<0.001)$ after a year of observation in the control group.

Conclusions: This study results should encourage the establishment of education as a permanent element of the LSG procedure.
\end{abstract}

Key words: morbid obesity, bariatric surgery, education.

\section{Introduction}

As a result of the constantly growing number of people with obesity and the low effectiveness of conservative obesity treatment, with approximately $13 \%$ of the world's adult population currently having a body mass index (BMI) of $\geq 30 \mathrm{~kg} / \mathrm{m}^{2}$ [1], the popularity of bariatric surgery has been systematically increasing. In Poland, there are no current epidemiological data on nation- wide obesity rates. The NATPOL PLUS study, conducted in a representative group of Poles in 2002, indicated that $53 \%$ of respondents were overweight and $19 \%$ were obese. A pilot study, conducted in 2003 as part of the "Polish 400 Cities Project", found that $46.4 \%$ of men and $38.9 \%$ of women were overweight, and $28.0 \%$ of women and $27.3 \%$ of men were obese [2].

Currently, among the numerous surgical methods, laparoscopic sleeve gastrectomy (LSG) has a high

\section{Address for correspondence}

Prof. Jolanta Lewko, Department of Integrated Medical Care, Medical University of Bialystok, 7 a Skłodowskiej St, 15-086 Bialystok,

Poland, phone: +48 663749 491, e-mail: jola.lewko@wp.pl 
success rate in treating pathological obesity as well as obesity-related illnesses, including diabetes (T2DM) and metabolic syndrome (MS) [3]. LSG belongs to a group of restrictive procedures. It consists of laparoscopic vertical stomach resection of the greater curvature, reducing the volume to $<100 \mathrm{ml}$, leaving the pylorus intact [3].

It is estimated that the economic costs of treating obesity and its complications in Poland amounts to $20-30 \%$ of expenses on health care. Approximately two thousand patients with morbid obesity are operated on annually. It is currently believed that treating patients with morbid obesity should be multifaceted/multidirectional. Long-term weight loss is dependent on the correctness of the LSG surgical method, but also requires a high level of motivation to abide by set postoperative recommendations on diet, vitamin supplementation [4-6], physical activity [7], systematic check-ups, and other actions resulting from the general health status [8-12].

A few studies have been conducted that suggest a positive effect of applying a non-pharmacological therapy when treating obesity. The effect of conducting varied education sessions on the treatment process of patients with morbid obesity undergoing LSG has not been explored. It has not yet been explained whether individual education of the patient can contribute to long-term success in weight reduction after bariatric treatment.

\section{Aim}

The aim of this study was to implement and compare the effects of different education methods (three organized education sessions versus receiving one-time written information in the form of a guidebook) on patient involvement in abiding by lifestyle recommendations after LSG bariatric treatment.

\section{Material and methods}

\section{Study design}

This retrospective observational study included 160 patients with morbid obesity who fulfilled the criteria for surgery, in accordance with the Interdisciplinary European guidelines for surgery for severe (morbid) obesity from 2007 [13]; they were qualified at our hospital's Surgical Outpatient Clinic \pm 6 weeks before the LSG procedure, and then operated on in the Department of Surgery from 2015 to 2017.
Each participant underwent multiple consultations with specialists (of endocrinology, diabetology, psychology, and gynecology for women) in order to assess obesity-related diseases and to prepare for the procedure.

Imaging examinations such as a chest X-ray, abdominal cavity ultrasound, and gastroscopy were carried out to exclude possible gastrointestinal tract pathologies. Echocardiography was done in patients with coronary artery disease. In patients with a risk of venous thrombosis occurrence, Doppler ultrasound evaluation of the lower limbs was performed. In patients with chronic obstructive pulmonary disease (COPD), or in cases of suspicion of sleep apnea, polysomnography or rhinomanometry was carried out.

All 160 patients were under the care of the same medical team during treatment.

During qualification for bariatric surgery, the nurse at the Surgical Outpatient Clinic informed patients how to prepare for the LSG procedure. She conducted and documented individual 30-minute interviews with each patient before including them in the study. The aim of the interview was to collect information on dieting history/weight loss attempts, comorbidities, the effect of obesity on daily life, data on dietary habits, physical activity, lifestyle, level of motivation to commit to bariatric treatment, and the patient's educational expectations. All patients signed a consent form to participate in the study. All procedures were designed, conducted, and reported in compliance with the Declaration of Helsinki and approved by the Bioethics Committee of the Medical University of Bialystok. Consent from the committee was received in written form, no. R-I-002/343/2016.

\section{Interventions}

Education Session Study Participants: After sleeve gastrectomy, 100 patients with whom three education sessions were planned were enrolled in the study.

The larger group of patients examined compared to the control group resulted from the team's large educational capabilities and expectations of the respondents.

\section{First education session}

A nurse organized the first education session on the day of discharge from the department, in a separate room to create a comfortable atmosphere 
during the one-on-one conversation with the patient. The provided information pertained to postoperative wound care: follow-up frequency; remaining on a properly balanced low-calorie diet (from 1000 to $1400 \mathrm{kcal}$ and minimal daily consumption of 60-70 g of protein), consistent with the guidelines developed by the University of Nevada School of Medicine [14]; the causes and symptoms of dumping syndrome; lifestyle modifications; and recommended physical activity [15] of moderate intensity at least $150 \mathrm{~min} /$ week, and eventually $300 \mathrm{~min} /$ week, including strength training 2-3 times a week. Patients were advised to keep a self-control diary. Session duration was from a minimum of $1 \mathrm{~h}$ to a maximum of $2 \mathrm{~h}$, depending on the individual aptitudes and needs of the patient. The patient received comprehensive explanations to questions asked within the realm of the issues covered.

\section{Second education session}

Six months after LSG, the surgeon who operated on the patient assessed weight, BMI, and the comorbidities that occurred prior to surgery, documented new health problems, and evaluated currently taken drugs and laboratory test results (including hemoglobin, hematocrit, vitamin $B_{12}$ concentration, and glycated hemoglobin $\left(\mathrm{HbA}_{1 \mathrm{c}}\right)$ if the patient had diabetes or had impaired glucose tolerance before the procedure). If there were any additional symptoms, the surgeon would recommend additional testing or examinations. Then, the nurse obtained a report from the patient and documented information pertaining to adhering to recommendations on diet, lifestyle, and physical activity. She answered questions and gave advice on meal preparation, recommended and prohibited products, suggested forms of physical activity, as well as reviewing individual health problems reported by the patient. She emphasized the necessity to maintain changes.

\section{Third education session}

The aim of this session was to summarize the entire education program. During the check-up, the surgeon assessed the patient's general health, weight loss, and BMI. The nurse asked each patient individually if they had expanded their knowledge and if they had applied it practically. Patients filled in a short evaluation. They were also asked to indi- cate an area of knowledge that they had not learned about but would like to expand. Patients were informed about the need to adhere to recommendations in the future.

The control group consisted of 60 patients who underwent sleeve gastrectomy; they fulfilled the same inclusion criteria for the study as the patients in the study group. After the LSG procedure before discharge from the department, they received onetime written recommendations (the exact same ones as the patients in the study group) in the form of a guidebook. These patients were unable to attend educational sessions due to their work, distant place of residence, or access difficulties; therefore, patients with higher pre-operative BMIs were included in this group.

\section{Assessment of conducted education sessions}

The knowledge of the 160 patients after LSG regarding adhering to recommendations on diet, lifestyle, and physical activity was assessed using a proprietary questionnaire. It was prepared on the basis of prior pilot studies and data from the literature $[14,15]$. The level of motivation to abide by the received recommendations was assessed on a 10 point visual analog scale (VAS) with a graphic section 0-10 cm in length, where patients subjectively assessed their level of motivation. On the two ends of the $10 \mathrm{~cm}$ section were two opposite positions: 0 indicated no motivation, while 10 indicated maximum motivation. Along this line there were word descriptions (low, medium, high).

These tools were used three times. Patients from the study group were assessed during the education sessions, while patients from the control group were assessed during check-ups.

\section{Surgical technique}

Sleeve gastrectomy (SG) was done laparoscopically by one team of surgeons (one head surgeon and two assisting). The surgery technique evolved with experience, where at the beginning five trocars were used, while currently three to four ports are used. Stomach calibration was done using a 32-36 Fr tube, starting the resection at 2-6 $\mathrm{cm}$ from the pylorus. The anastomosis was tested for any leaks using methylene blue. The procedure lasted on average about 64 min. 


\section{Statistical analysis}

In the statistical analysis, the $\chi^{2}$ test was used to assess correlations between qualitative independent variables. Normal distribution was verified using the Kolmogorov-Smirnov test with the Lilliefors correction, as well as the Shapiro-Wilk test. Normal distribution of the quantitative variables was not found. The nonparametric Mann-Whitney test was used to compare ordinal variables and quantitative variables with non-normal distribution in the case of two groups. To compare dependent variables, we used the Wilcoxon matched pairs test in the case of two variables, and the Friedman test in the case of many variables.

The results were considered statistically significant at $p<0.05$. Statistical analysis was performed using StatSoft Statistica 12.0 software.

\section{Results}

A total of 160 patients were recruited to the study. The group of patients that participated in the education sessions consisted of 57 women and
43 men, aged $54 \pm 10.9$ years; the control group consisted of 35 women and 25 men, aged $49.5 \pm 10.6$ years. The main clinical characteristics are presented in Table I.

Based on the obtained materials, we found that 6 months after LSG, the BMI $\left(38.28 \pm 6.93 \mathrm{~kg} / \mathrm{m}^{2}\right)$ of the education session participants had a statistically significant decrease $(p<0.001)$ compared with their $\mathrm{BMI}$ before the procedure $\left(44.25 \pm 7.24 \mathrm{~kg} / \mathrm{m}^{2}\right)$. After a year of observation, we also confirmed a statistically significant $(p<0.01)$ decrease in BMI to $33 \pm 5.7 \mathrm{~kg} / \mathrm{m}^{2}$. The time that passed after the procedure also had a statistically significant $(p<0.001)$ effect on \%EWL (observed excess weight loss) and \%EBMIL (observed excess BMI loss after the procedure), both 6 months and 1 year after (Figure 1).

We also observed a statistically significant $(p<0.001)$ decrease in BMI $(48.62 \pm 5.64$ before the procedure) in the control group to $44.41 \pm 6.04$ at 6 months after, and $41.7 \pm 5.92$ one year after LSG. Simultaneously, after 1 year of observation, we noted statistically significant $(p<0.001)$ changes in $\%$ EWL and \%EBMIL (Figure 1).

Table I. Characteristics of the studied group of patients

\begin{tabular}{|c|c|c|c|}
\hline Parameter & $\begin{array}{l}\text { Group participating in } \\
\text { education sessions }\end{array}$ & $\begin{array}{l}\text { Group receiving information in } \\
\text { written form/Control group }\end{array}$ & $P$-value \\
\hline Age, mean \pm SD [years] & $54 \pm 10.9$ & $49.5 \pm 10.6$ & NS \\
\hline Sex, F/M & $57 / 43$ & $35 / 25$ & NS \\
\hline $\begin{array}{l}\text { Source of income (work/welfare/retire- } \\
\text { ment pension/student) }\end{array}$ & $79 / 6 / 9 / 6$ & $48 / 4 / 5 / 3$ & NS \\
\hline Place of residence (village/city) & $27 / 73$ & $9 / 51$ & NS \\
\hline Education (vocational/secondary/higher) & $35 / 29 / 36$ & $12 / 25 / 23$ & NS \\
\hline \multicolumn{4}{|l|}{ Comorbidities: } \\
\hline Type 2 diabetes (\%) & 38.8 & 36.6 & 0.002 \\
\hline Hypertension (\%) & 35.2 & 28.7 & $<0.001$ \\
\hline Dyslipidemia (\%) & 36.3 & 29.6 & $<0.001$ \\
\hline Coronary artery disease (\%) & 11.5 & 7.4 & NS \\
\hline COPD $(\%)$ & 13.7 & 10.5 & NS \\
\hline Cholelithiasis (\%) & 15.7 & 14.8 & 0.025 \\
\hline Lower limb varicose veins (\%) & 15.4 & 13.07 & $<0.001$ \\
\hline Anthropometric measurements: & & & NS \\
\hline Height (F/M) [m] & $1.69 \pm 0.4 / 1.71 \pm 0.2$ & $1.66 \pm 0.5 / 1.69 \pm 0.3$ & \\
\hline Weight (F/M) [kg] & $148.7 \pm 22.6 / 163.1 \pm 21.7$ & $139.8 \pm 23.6 / 163 \pm 24.2$ & 0.010 \\
\hline BMI (F/M) $\left[\mathrm{kg} / \mathrm{m}^{2}\right]$ & $43.15 \pm 7.2 / 46.06 \pm 7.1$ & $47.8 \pm 5.6 / 50.1 \pm 5.64$ & $<0.001$ \\
\hline
\end{tabular}


A

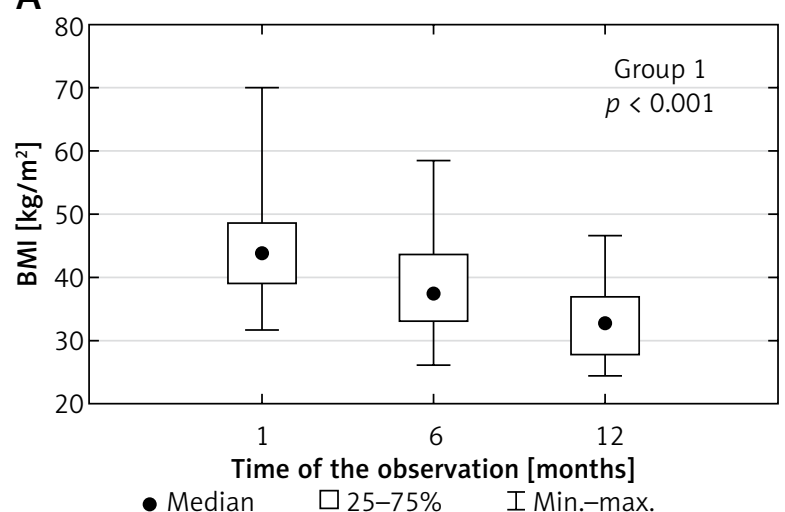

C

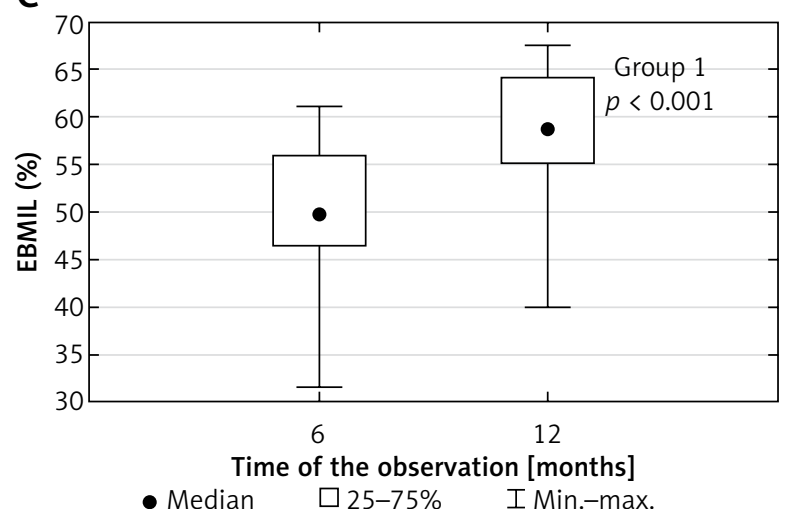

E

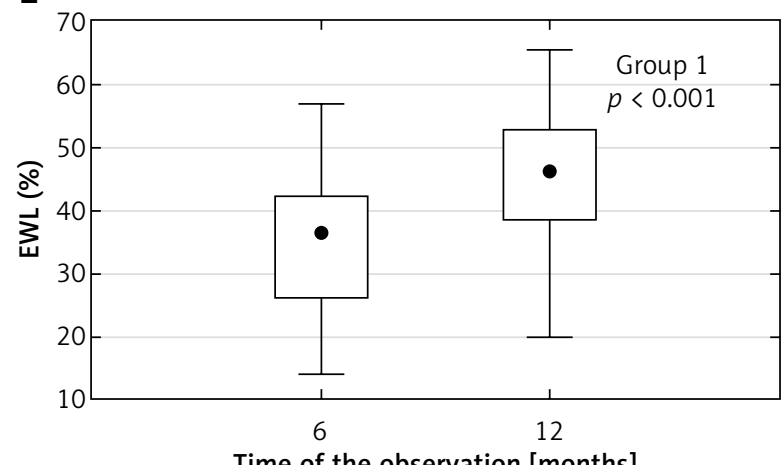

- Median

Time of the observation [months]

Figure 1. Postoperative changes in BMI in the studied groups of patients during 1 year of observation

Group 1 - group participating in education sessions; group 0-group receiving information in written form (control group).

After analyzing the postoperative results pertaining to abiding by dietary recommendations, we found a positive effect of the procedure and education. We observed statistically significant differences between the study group and the control group in terms of the undertaken dietary modifications 6 months after $(p<0.001)$ the procedure, and during the 1-year observation, which pertained to consum-
B

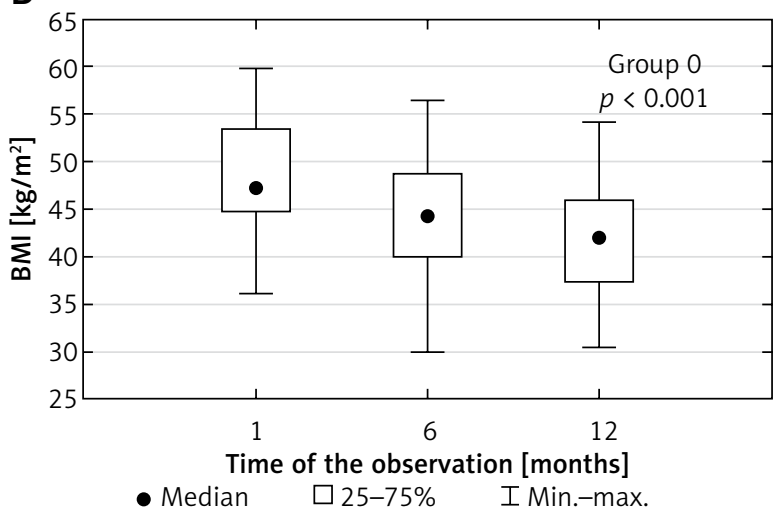

D

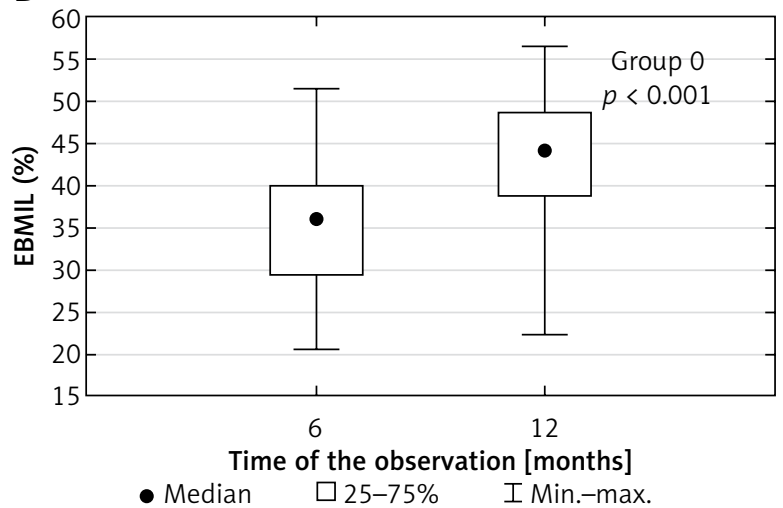

$\mathrm{F}$

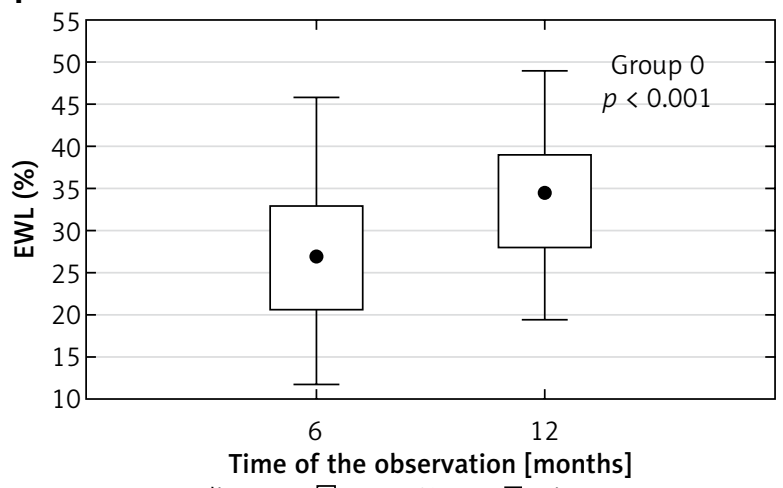

- Median $\square 25-75 \%$ IMin-max. ing small portions $(p<0.001)$, precise chewing of food $(p<0.018)$, and food intake at short intervals every 3-4 h $(p<0.007)$ (Table II). In terms of adherence to recommended and prohibited products in the diet, the amount of liquids consumed was not statistically significant.

Changes in the participants' physical activity were analyzed, distinguishing between the study group and 
Table II. Adherence to certain dietary recommendations in the study group and the control group of patients

\begin{tabular}{|c|c|c|c|c|c|}
\hline \multirow[t]{2}{*}{ Variable } & \multicolumn{2}{|c|}{$\begin{array}{l}\text { Group participating in } \\
\text { education sessions }\end{array}$} & \multicolumn{2}{|c|}{ Control group } & \multirow[t]{2}{*}{$P$-value } \\
\hline & Yes & No & Yes & No & \\
\hline $\begin{array}{l}\text { Compliance with dietary recommendations after } \\
6 \text { months: small portions }\end{array}$ & $100(100 \%)$ & $0(0 \%)$ & $39(65 \%)$ & $21(35 \%)$ & 0.001 \\
\hline Precise chewing of food & $87(87 \%)$ & $13(13 \%)$ & $29(48.3 \%)$ & $31(51.7 \%)$ & 0.001 \\
\hline Food intake at short intervals every $3-4 \mathrm{~h}$ & $94(94 \%)$ & $6(6 \%)$ & $42(70 \%)$ & $18(30 \%)$ & 0.001 \\
\hline Protein intake (0.8-1 g/kg of ideal body weight) & $72(66.7 \%)$ & $28(53.8 \%)$ & $36(33.3 \%)$ & $24(46.2 \%)$ & NS \\
\hline $\begin{array}{l}\text { Compliance with dietary recommendations after } \\
1 \text { year: small portions }\end{array}$ & $100(100 \%)$ & $0(0 \%)$ & $50(83.3 \%)$ & $10(16.7 \%)$ & 0.001 \\
\hline Precise chewing of food & $56(56 \%)$ & $44(44 \%)$ & $22(36.7 \%)$ & $38(63.3 \%)$ & 0.018 \\
\hline Food intake at short intervals every $3-4 \mathrm{~h}$ & $85(85 \%)$ & $15(15 \%)$ & $20(57.1 \%)$ & $40(32 \%)$ & 0.007 \\
\hline Protein intake (0.8-1 g/kg of ideal body weight) & $47(77 \%)$ & $53(53.5 \%)$ & $14(23 \%)$ & $46(46.5 \%)$ & 0.003 \\
\hline
\end{tabular}

Table III. Physical activity in the study group and the control group of patients during 1 year of observation

\begin{tabular}{|c|c|c|c|}
\hline Variable & $\begin{array}{l}\text { Group participating in } \\
\text { education sessions }\end{array}$ & Control group & $P$-value \\
\hline Physical activity after 6 months: daily walks 30 min: & $56(56 \%)$ & $6(10 \%)$ & 0.001 \\
\hline Irregular walks 30 min & $35(35 \%)$ & $36(30 \%)$ & \\
\hline Swimming every $2-3$ days 30 min & $2(2 \%)$ & $0(0 \%)$ & \\
\hline Swimming irregularly 30 min & $6(6 \%)$ & $8(13.3)$ & \\
\hline No physical activity & $1(1 \%)$ & $10(16.7)$ & \\
\hline Physical activity after 1 year: daily walks 30 min: & $74(74 \%)$ & $17(28.3 \%)$ & 0.001 \\
\hline Irregular walks 30 min & $16(16 \%)$ & $35(68.6)$ & \\
\hline Swimming every $2-3$ days 30 min & $8(8 \%)$ & $0(0 \%)$ & \\
\hline Swimming irregularly $30 \mathrm{~min}$ & $2(2 \%)$ & $2(3.3 \%)$ & \\
\hline No physical activity & $0(0 \%)$ & $6(10 \%)$ & \\
\hline
\end{tabular}

the control group. The results remained statistically significant $(p<0.001)$ at every stage of observation. In the study group, 1 (1\%) patient participating in the education sessions admitted to no physical activity 6 months after the procedure. After a year, all study group participants reported increased physical activity. In the control group, after 6 months of observation $10(16.7 \%)$ patients, and after a year $6(10 \%)$, did not increase their physical activity (Table III). Undertaking other forms of activity, as reported by the participants, was not found to be statistically significant.

In the study, we assessed participants' level of motivation to abide by the received lifestyle recom- mendations after LSG during a 1-year observation, using a 10-point scale. We noted that in the group of patients who participated in the education sessions the motivation level was high, both after 6 months $(9.55 \pm 0.62)$ and 1 year $(9.39 \pm 0.66)$. In the control group, which received recommendations in written form, the motivation level was high before the procedure $(9.55 \pm 0.53)$, but it decreased after a year (8.50 $\pm 1.12)$, which was statistically significant $(p<0.001)$ (Table IV).

The group participating in the education sessions evaluated the form of education as 9.0 (51 patients, $51 \%$ ) and 10 points (49 patients, 49\%). 
Table IV. Subjective assessment of motivation to abide by recommendations and systematic check-ups after LSG during 1 year of observation on the VAS scale

\begin{tabular}{|lccc|}
\hline Time & $\begin{array}{c}\text { Group participating in education } \\
\text { sessions }\end{array}$ & Control group & $P$-value \\
\hline Before surgery & $9.55 \pm 0.62$ & $9.55 \pm 0.53$ & NS \\
\hline 6 months after surgery & $9.44 \pm 0.68$ & $9.15 \pm 0.93$ & NS \\
\hline Year after surgery & $9.39 \pm 0.66$ & $8.50 \pm 1.12$ & 0.001 \\
\hline
\end{tabular}

Table V. Evaluation of the form of conducted education in the study group and the control group during 1 year of observation on the VAS scale

\begin{tabular}{|c|c|c|c|}
\hline VAS Scale & $\begin{array}{c}\text { Group participating in education } \\
\text { sessions }\end{array}$ & Control group & $P$-value \\
\hline 3.0 & $0(0 \%)$ & $3(5 \%)$ & 0.001 \\
\hline 4.0 & & $3(5 \%)$ & \\
\hline 5.0 & & 10 (16.7\%) & \\
\hline 6.0 & & $14(23.3 \%)$ & \\
\hline 7.0 & & $14(23.3 \%)$ & \\
\hline 8.0 & & $14(23.3 \%)$ & \\
\hline 9.0 & $51(51 \%)$ & $2(3.3 \%)$ & \\
\hline 10.0 & 49 (49\%) & $0(0 \%)$ & \\
\hline
\end{tabular}

Patients in the control group did not give the maximum amount of 10 points, and expressed their opinions by giving from 3 (3 patients, 5\%) to 9 points (2 patients, $3.3 \%$ ), which was statistically significant $(p<0.001)$ (Table V).

\section{Discussion}

Laparoscopic sleeve gastrectomy is a relatively new method among the bariatric procedures. The results of a 1-year observation showed that weight reduction can be greater after LSG than other bariatric procedures [16]. It is currently a more and more frequently performed one-phase procedure in the treatment of obesity. LSG is recommended even in patients with high perioperative risk connected to comorbidities, due to the short duration of the procedure (80-120 min) and minimal risk of complications [17]. Our 1-year observation results confirm the beneficial effect of the procedure in terms of a decrease in BMI in the study group to $33 \pm 5.7 \mathrm{~kg} / \mathrm{m}^{2}$, EWL by $45 \%$, and EBMIL by $55 \%$, which are similar findings to other authors' results [18-20]. In the control group, the initial BMI was $48.62 \pm 5.64 \mathrm{~kg} / \mathrm{m}^{2}$; thus it was more difficult to achieve success. This study confirms the beneficial effect of lower initial weight parameters for obtaining a lower BMI after surgery.

Regardless of the type of bariatric procedure, making lasting lifestyle changes in the postoperative process is essential for patients wanting to obtain an optimal reduction in weight. Not adhering to recommendations can result in weight regain [21]. Only a few studies have assessed the effect of compliance with diet, physical activity, and lifestyle changes on weight loss after LSG [22], and most pertain to Rouxen-Y gastric bypass (RYGB) [23]. We confirmed that the three education sessions we conducted in the study group after LSG, which motivated the patients and indicated how to comply with dietary, physical activity, and lifestyle recommendations, had a significant impact on weight loss. Our study also confirms the high level of motivation to continue with the developed changes after 1 year of observation. There are several factors to explain the beneficial effect of education. The comprehensive approach during the education sessions could have increased the participants' skills in preparing meals, selecting ingredi- 
ents, and eliminating prohibited foods. Conducting the sessions in critical moments, directly, 6 months and 1 year after surgery, equipped the patients with knowledge and enabled a reduction in the number of calories consumed, which has been confirmed by other studies [15]. The control group, which received only written information, obtained weight loss and abided by the written recommendations, although to a lesser extent than the study group. The differences were evident particularly in motivation to adhere to recommendations and check-ups, which was significantly lower $(p<0.001)$ after a year of observation.

Literature analysis confirms the positive influence of education on bariatric surgery $[24,25]$. The analyzed studies distinguish the time of conducting the education programs as preoperative and postoperative. They indicate that education on lifestyle changes before the procedure increases the effectiveness of surgical intervention. In our study, we divided the scope of education into two stages. In the preoperative stage, we informed patients of the methods of preparing for LSG and assessed their lifestyles. Other elements of the education program, including diet and lifestyle, were conveyed to the patients before discharge from the department. Undoubtedly, both forms of education - preoperative and postoperative - are appropriate. We decided that conveying the necessary information in stages would enable patients to acquire it more permanently.

Regular exercise is associated with obtaining better weight loss results after bariatric treatment $[9,15,26]$. The beneficial effects are caused by an increased duration of physical activity after LSG compared with before the procedure. In our study group, 1 (1\%) patient participating in the education sessions admitted to no physical activity 6 months after the procedure, but after a year all participants reported doing exercise adapted to individual abilities. In the control group, 10 (16.7\%) participants had a sedentary lifestyle after 6 months, and $6(10 \%)$ after 1 year. The study results indicated that the most common forms of physical activity were walking and swimming. After half a year, daily 30-minute walks were done by $56(56 \%)$ participants in the education sessions, and 74 (74\%) after a year, which was a significantly $(p<0.001)$ more frequent form of physical activity compared with the control group. According to recommendations [15], strength training should be undertaken two to three times a week. The obtained data indicated that only a few of the studied patients undertook this form of exercise. However, our results correlate with the data published in the literature [27].

Although our study had a positive impact on weight reduction and lifestyle changes after LSG, there are a number of limitations. The main factor interfering with the study may be the different size of the study and control groups. Education sessions and the scope of their content were determined by the nurse and the bariatric surgeon. However, in terms of establishing a particular diet and assessment of adherence, the participation of a nutritionist would be a better solution. Similarly, the recommendations pertaining to the amount of exercise per week, duration, and type of exercise could have been prepared in a professional manner by a physiotherapist. We recommend a replication of our study with a multidisciplinary team.

The control group only received a written guidebook with information on diet, physical activity, and lifestyle recommendations before discharge from the department. After a year of observation, this group had reduced motivation to comply with recommendations. However, the fact that we noted significant weight loss in this group could just be the effect of the procedure alone. Furthermore, a longer study duration may be necessary to assess the role of education sessions in LSG effectiveness.

It cannot be excluded that the efficacy of bariatric treatment was enhanced by following the recommendations of the guide.

\section{Conclusions}

On the basis of successful weight loss evaluated using EWL\% and EBMIL\%, sleeve gastrectomy is an effective surgical method in morbid obesity treatment.

Based on the results it can be concluded that the educational sessions increased patient adherence to lifestyle recommendations. Due to the higher pre-operational level of BMI in the control group, the effectiveness of written information in the form of a guide is difficult to assess. The reduction in body weight could have been the result of surgery, but the recommendations could have enhanced this effect. These study results should encourage the establishment of education as a permanent element of the LSG procedure. 


\section{Acknowledgments}

The authors thank the cooperating institutions and participants.

\section{Conflict of interest}

The authors declare no conflict of interest.

\section{References}

1. WHO. Fact Sheet. 311. Geneva, Switzerland: World Health Organization; 2015. Obesity and overweight. http://www.who.int/ mediacentre/factsheets/fs311/en/

2. Stanowski E, Wyleżoł M, Paśnik K. Laparoscopy in bariatric surgery in Poland - present status. Videosurgery Miniinv 2007; 2: 18-23.

3. Khorgami Z, Shoar S, Andalib A, et al. Trends in utilization of bariatric surgery, 2010-2014: sleeve gastrectomy dominates. Surg Obes Relat Dis 2017; 13: 774-8.

4. Dagan SS, Keidar A, Raziel A, et al. Do bariatric pateints follow dietary and lifestyle recommendations during the first postoperative year? Obes Surg 2017; 27: 2258-71.

5. Thibault R, Pichard C. Overview on nutritional issues in bariatric surgery. Curr Opin Clin Nutr Metab Care 2016; 19: 484-90.

6. Jastrzębska-Mierzyńska M, Ostrowska L, Hady RH, et al. The impact of bariatric surgery on nutritional status of patients. Videosurgery Miniinv 2015; 10: 115-24.

7. Egberts K, Brown WA, Brennan L, et al. Does exercise improve weight loss after bariatric surgery? A systematic review. Obes Surg 2012; 22: 335-41.

8. Neagoe RM, Mureşan M, Bancu S, et al. Results of laparoscopic sleeve gastrectomy - 5-year follow-up study in an eastern European emering bariatric center. Obes Surg 2017; 27: 983-89.

9. Nijamkin MP, Campa A, Sosa J, et al. Comprehensive nutrition and lifestyle education improves weight loss and physical actyvity in Hispanic Americans following gastric bypass surgery: a randomized controlled trial. J Acad Nutr Diet 2012; 112: 382-90.

10. Wróblewski E, Świdnicka-Siergiejko A, Hady RH, et al. Variation in blood levels of hormones in obese patients following weight reduction induced by endoscopic and surgical bariatric therapies. Cytokine 2016; 77: 56-62.

11. Hady RH, Dadan J, Gołaszewski P. 100 obese patients after laparoscopic adjustable gastric banding-the influence on BMI, gherlin and insulin concentration, parameters of lipid balance and co-morbidites. Adv Med Sci 2012; 57: 58-64.

12. Hady RH, Zbucki Rt, Łuba ME, et al. Obesity as a social disease and the influence of environmental factors on BMI in own material. Adv Clin Exp Med 2010; 19: 369-78.

13. Fried M, Hainer V, Basdevant A, et al. Bariatric Scientific Collaborative Group Expert Panel. Interdisciplinary European guidelines for surgery for severe (morbid) obesity. Obes Surg 2007; 17: 260-70.

14. Kulick D, Hark L, Deen D. The bariatric surgery patient: a growing role for registred dietitians. J Am Diet Assoc 2010; 110: 593-9.

15. Mechanick JI, Youdim A, Jones DB, et al. Clinical practice guidelines for the perioperative nutritional, metabolic, and nonsurgi- cal suport of the bariatric surgerypatient-2013 update: cosponsored by American Association of Clinical Endocrinologists, The Obesity Society, and American Society for Metabolic \& Bariatric Surgery. Obesity 2013; 3 Suppl 1: S1-27.

16. Angrisani L, Santonicola A, lovino P, et al. Bariatric surgery wordwide 2013. Obes Surg 2015; 25: 1822-32.

17. Noel P, Nedelcu M, Eddbali I, et al. What are long-term results 8 years after sleeve gastrectomy? Surg Obes Relat Dis 2017; 13: 1110-5.

18. Sierżantowicz R, Lewko J, Trochimowicz L, et al. Effectiveness of bariatric procedures based on selected laboratory parameters of patients from rural areas in Polish population. Adv Clin Exp Med 2017; 26: 679-86.

19. Doležalova-Kormanova K, Buchwald JN, Skochova D. Five-year outcomes: laparoscopic greater curvature plication for treatment of morbid obesity. Obes Surg 2017; 27: 2818-28.

20. Szczepaniak JP, Owens ML, Shukla H, et al. Comparability of weight loss reporting after gastric bypass and sleeve gastrectomy using BOLD dtata 2008-2011. Obes Surg 2015; 25: 788-95.

21. Bond DS, Phelan S, Leahey TM, et al. Weight-loss maintenance in successful weight losers: surgical vs. non-surgical methods. Int J Obes 2009; 33: 173-80.

22. Stefura T, Skomarovska O, Wysocki M, et al. Challenges associated with bariatric surgery - a multi-center report. Videosurgery Miniinv in press, 2019; doi.org/10.5114/wiitm.2019.81370

23. Sheets CS, Peat CM, Berg KC, et al. Post-operative psychological predictors of outcome in bariatric surgery. Obes Surg 2015; 25 : 33045.

24. Groller KD. Systematic review of patient education practices in weight loss surgery. Surg Obes Relat Dis 2017; 13: 1072-85.

25. Kostecka M, Bojanowska M. Problems in bariatric patient care - challenges for dieticians. Videosurgery Miniinv 2017; 12: 207-15.

26. Jacobim D, Ciangura C, Couet C, et al. Physical activity and weight loss following bariatric surgery. Obes Rev 2011; 12: 366-77.

27. King WC, Chen JY, Bond DS, et al. Objective assessment of changes in physical activity and sedentary behavior: pre- through 3 years post-bariatric surgery. Obesity 2015; 23: 1143-50.

Received: 28.02.2019, accepted: 27.07.2019. 